\title{
Determinants of career choice among G.C.E. Ordinary Level students in Sri Lanka with special reference to the Kalutara District, Western Province
}

Sri Lanka Journal of Social Sciences and Humanities Volume 2 Issue 1, February 2022: 1-9 ISSN: $2773692 X$ (Online), 27736911 (Print) Copyright: (C) 2021 The Author(s)

Published by Faculty of Social Sciences and Languages, Sabaragamuwa University of Sri Lanka Website: https://www.sab.ac.lk/sljssh DOI: http://doi.org/10.4038/sljssh.v2i1.51

\author{
Swaris, W.D.K.J.N. ${ }^{1, *}$ \\ ${ }^{1}$ University of Peradeniya, Peradeniya, 20400, Sri Lanka.
}

Received: 05 March, 2021, Revised: 30 July, 2021, Accepted: 16 September, 2021.

How to Cite this Article: Swaris, W.D.K.J.N. (2022). Determinants of career choice among G.C.E. ordinary level students in Sri Lanka with special reference to the Kalutara District, Western province. Sri Lanka Journal of Social Sciences and Humanities, 2(1), 1-9.

\begin{abstract}
Career decisions or choices are important in deciding the future of a person. Although the area of study; career choice has been studied a few times previously among graduates, university students, and A/L students, no studies have been conducted among G.C.E. Ordinary Level Students. The main purpose of this mix-convergent non-experimental study was to scrutinize the career choice of G.C.E.O/L students in Sri Lanka. Two samples, including 110 students by stratified sampling and 10 teachers by random sampling, were recruited. Students studying at 4 types of schools in Kalutara District were urged to complete a self-administered questionnaire, and 10 teachers were interviewed. SPSS software was used to analyze quantitative data with intense analysis, whereas content analysis was used to analyse qualitative data. Based on the ISCO-08 classification, a subcategory of 'professionals' was preferred mostly by G.C.E.O/L students. Above all, 'personal interest' was found to be the most influential determinant of career choice. $59.1 \%$ of the students were not aware of career guidance programs available in the country, while $7.3 \%$ have not yet decided on a career choice. Different social, economic, and personal or psychological impacts of choosing a career are discussed in the current report. The findings of the research would pave the path for future researchers to investigate more on determinants of career choice of students and the issues faced by the students when deciding a career. More implications for career guides, counselors in the educational field, and educational psychologists would be discussed.
\end{abstract}

Keywords: Career choice of students, Career guidance, Determinants of career choice, ISCO classification of occupations

\section{INTRODUCTION}

A career is defined as the series of jobs or occupations undertaken by an individual in a particular area of work for a period, with progressive opportunities involving more responsibility over time (Bradbery, 2011). Deciding on a career path is a huge part of every human. The decision taken by the students about their career path would impact their lifestyle or the other stages of life. Many changes in the job market could be seen over time with the economic growth, improvement in technology, demographic shifts, and changes in consumer taste. Positive and negative effects for employment are available. With all these economic and social developments, fields of jobs also would continue to grow and change over time (Su, 2004). Students choose a job or career based on different factors or reasons. These factors could be personal, economic, social, or other outside factors. Unlike other countries, the G.C.E. O/L exam is one of the critical hurdles to the students in Sri Lanka as it determines the ability to get qualified for the $A / L$ exam.

Considering the past G.C.E. O/L results from the year 2012 to $2019,70.21 \%$ of students are qualified for $A / L$ exams on average (Department of Examinations, 2019). In Sri Lanka, it is doubtful whether students study or face G.C.E. O/L with proper awareness of their career since it was found that most of the students (60 percent) had not taken part in any career guidance programmes. A good career guidance programme leads to a decrease in the dropout rate of students (National Education Commission, 2016). Hence, the current study intends to study the career choices of junior school students and the need for career guidance. Correspondingly, factors that determine their career choice or decisions, comparison of the determinants that affect career choice between the graduates/undergraduate and school students, are also assessed. While some students prefer higher education, others have to choose a career. Especially, those who are not qualified have to decide their career path. Therefore, the G.C.E. O/L exam plays a huge role in determining the future of the students. It is important to have knowledge or awareness of unconventional career choices available in the country or globally. The performance of school candidates at the G.C.E. O/L Examination from 2012 to 2019 is illustrated in Table 1.

The primary aim is to develop more sophisticated methods to investigate the factors that determine career choice among G.C.E.O/L students in Sri Lanka. Objectives of this study were discovering different career choices of $\mathrm{O} / \mathrm{L}$ students, comparing the determinants that affect career choice

\footnotetext{
* Corresponding author: Tel.: +94 76697 1726; Email: kjnilinaswaris@gmail.com (D) https://orcid.org/0000-0001-6409-0832
} 
between the graduates/undergraduate and school students, identifying the awareness of students on available career paths and career guidance programmes, identifying the different factors determining the career choice of students, identifying the problems that $\mathrm{O} / \mathrm{L}$ students in Sri Lanka face Table1: Performance of school candidates (1st attempt)

\begin{tabular}{|c|c|c|c|c|c|c|c|c|c|}
\hline \multicolumn{2}{|l|}{ Year } & 2012 & 2013 & 2014 & 2015 & 2016 & 2017 & 2018 & 2019 \\
\hline \multicolumn{2}{|c|}{ No. Sat (5 or more subjects) } & 268995 & 264772 & 257322 & 273224 & 286251 & 296812 & 296029 & 305427 \\
\hline \multirow{2}{*}{ Qualified for A/L } & Number & 174160 & 176534 & 177612 & 189428 & 200208 & 216815 & 222281 & 225539 \\
\hline & $\%$ & 64.74 & 66.67 & 69.02 & 69.33 & 69.94 & 73.05 & 75.09 & 73.84 \\
\hline \multirow{2}{*}{$\begin{array}{l}\text { Obtained } \\
\text { passes }\end{array}$} & Number & 4509 & 5737 & 5271 & 6102 & 8224 & 9960 & 9261 & 10201 \\
\hline & $\%$ & 1.68 & 2.17 & 2.05 & 2.23 & 2.87 & 3.36 & 3.13 & 3.34 \\
\hline \multirow{2}{*}{$\begin{array}{l}\text { Failed in all subjects } \\
\text { (Appeared for } 6 \text { or } \\
\text { more subjects) }\end{array}$} & Number & 11100 & 9444 & 8147 & 8698 & 8900 & 7308 & 5917 & 7007 \\
\hline & $\%$ & 4.13 & 3.57 & 3.17 & 3.18 & 3.11 & 2.46 & 2 & 2.29 \\
\hline
\end{tabular}

\section{LITERATURE REVIEW}

Several prior studies in the broader literature have examined factors or determinants that affect the career plan or the decision of undergraduates and graduates several times throughout the years in Sri Lanka and globally. Studies have shown that young men and women have different styles in choosing a career. Men have a more liberal and progressive style of thinking. Women prefer a hierarchical style of thinking (Kim, 2011). Job preference of job seekers is an important aspect of human management aspect especially to job offers, policy-makers, and job seekers. Unfortunately, most of the academic programmes offered by the higher educational institutes are not orientated towards the actual needs of job seekers. Using 257 management undergraduates of the University of Sri Jayewardenepura, factors concerned by the job seekers were tested (Perera, Perera, \& Priyanthika, 2010).

The relationship between parenting style or parental attachment and career indecision among 382 Turkish high school students was explored by Cenkseven-Onder, Kirdok, and Isik. Career decisiveness was found to be higher in students whose parents were authoritative or authoritarian. Similarly, career decisiveness was higher in students with a medium attachment to their parents (Cenkseven-Önder, 2017). Considering reported findings of Beggs et al., factors related to interest were rated highly over job characteristics, psychological and social benefits. Many students prefer their major according to their academic performances and ability (Beggs, Bantham, \& Taylor, 2008).

Another important determinant in a career choice is personality. Several studies support the idea that the students choose a major according to their belief that their personality type would fit in the job. Those who are confident are prone to settle for a career that they are comfortable with (Kim, 2011; Ryan, 2014). Vickneswaran and Nimalathasan Balasundaran discovered personal factors play the most influential role in career choice among undergraduate students (Vickneswaran \& Nimalathasan Balasundaran, 2013).

With the rapid development of the health sector in Sri Lanka, a wide range of disciplines for career advancement are provided for medical undergraduates. The decisions on the career of medical graduates are affected by a multitude of factors such as socio-cultural values, economics, and peer recognition influences. The effect of the career guidance programme on choosing a career and the influence of being exposed to different specialties in the curriculum on carrier when deciding their career choice, impacts of choosing a career and understanding the implications to improve awareness on career paths or choice for students in Sri Lankan context.

choice were tested (Pinto, Galketiya, Jayasingheararchchi, Bandara, \& Wijesinghe, 2016)

A study was conducted with college-oriented high school students from the rural Central Appalachia region of Virginia to explore how the context affects career choice. Using social cognitive career theory, pathways to career choice and relevant contextual factors were analyzed using interviews (Carrico, Holly . Matusovich, \& Paretti, 2017).

In recent studies, the role of career preference factors in predicting the employability of graduates was tested using a sample of 154 recently passed out graduates in management faculties as academics of five states owned leading Universities in Sri Lanka. It has been discovered that stability, expertise, varieties, and creativity are positively related to the employability of graduates. Conversely, managerial, independence, and autonomy do not display a relationship with the employability of graduates. The graduates pay more attention to their job security as they seek opportunities to demonstrate and apply the skills and knowledge gained when choosing a career. Freedom on the job and autonomy in the decision were not considered as factors that determine employability. They don't show a willingness to employ in positions that lead to authority. The results further suggest that employability is affected by psychological factors such as the career preference of the graduates (Wickramaratne, 2018).

Since guidance and counselling are rudimentary in most commonly rural areas and, in general, most students and parents are not aware of the job opportunities. These include different career options available in the world of work, self-employment, alternative skill development, and training options. This is more common in rural areas and generally non-existent (Hughes \& Balasuriya, 2003).

In the light of past literature of the factors or determinants that affect career choice could be categorized as personal factors, psychological factors, job-related factors and economic factors, social/environmental factors. Although these factors were assessed previously using graduates and undergraduate samples, no studies have been conducted using school students to the best of my knowledge.

To fill the gap in the current body of knowledge, this study came up with the following research questions.

1. What are the factors or determinants that affect the career choice of G.C.E. O/L students in Sri Lanka? 
2. Is there a difference between the determinants that affect the career choice of graduates/undergraduates and the determinants that affect the career choice of school students?

\section{METHODOLOGY}

The current study was designed mainly focusing on the career choice of G.C.E.O/L students.

A mixed convergent parallel study (non-experimental) was conducted to scrutinize the factors that affect the career choice of G.C.E.O/L students who are proficient in Sinhala or

Table 2: Current Study design

\begin{tabular}{|c|c|c|c|c|}
\hline Design type & $\begin{array}{l}\text { Implementation } \\
\text { sequence }\end{array}$ & Relative priority & $\begin{array}{l}\text { Stage of Integra- } \\
\text { tion }\end{array}$ & $\begin{array}{l}\text { theoretical per- } \\
\text { spective, }\end{array}$ \\
\hline Concurrent triangulation & $\begin{array}{l}\text { Concurrent col- } \\
\text { lection of quanti- } \\
\text { tative and quali- } \\
\text { tative }\end{array}$ & $\begin{array}{l}\text { equal priority is } \\
\text { given for both } \\
\text { quantitative and } \\
\text { qualitative }\end{array}$ & $\begin{array}{l}\text { Interpretation or } \\
\text { Analysis }\end{array}$ & Not present \\
\hline
\end{tabular}

The current research is occupied with a variant of the Triangulation Design, which is the 'convergence model'

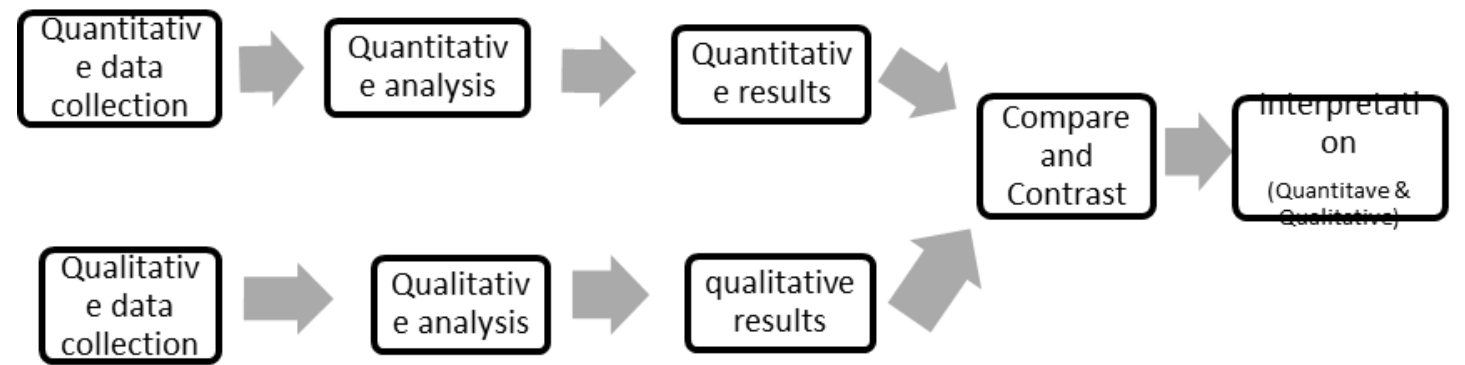

\section{Figure 1: Convergence model}

In this model, the quantitative and qualitative data were analyzed separately and results were converged by comparing and contrasting the results. This was used in the current study as it is effective in comparing and validating results. This is used to make valid and well-substantiated conclusions about a single concept/ phenomenon.

The level of rating how the factors affect the career choice of decisions of students and response of awareness on career guidance programmes were assessed as predictor variables/independent variables for the current study. Gender, educational division, and type of school were the identified confounding variables.

\section{Participants}

\section{Population}

The population of this study comprised all the G.C.E. O/L students from Kalutara district. including 420 government schools, 402 provincial schools, 18 national schools, 8 Private and 16 international schools. Two samples were included in the current study

\section{Sample 1:}

Since the stratified sampling was used in the current study, the total population was divided into subcategories, and the data which represent each sub-group/category was taken. Grade 11 students from different schools in Kalutara district (size $=110$ students) including four subcategories of schools as National schools, Provincial schools, Private schools /Semi-Government and International schools were recruited by Disproportionate stratified sampling based on the
English in the Kalutara District (Western Province), Sri Lanka. The research is based purely on primary data.

Mixed method research design or approach combines both qualitative and quantitative forms of data with philosophical assumptions. The overall strength of the research is higher than pure quantitative research or qualitative research. Four questions were proposed by Creswell, which should be addressed by a mixed-method research design. These include major aspects such as implementation sequence, relative priority, stage of integration, and theoretical perspective (Creswell, 2009). Based on these questions, the current study design is summarized in the table 2 . 
the ease of recruiting the expected participants. Consent was taken from the participants through along with the description of participant information when filling out the questionnaire and before the interviews. It should be read carefully and marked as read to get consent. The questionnaire was given to the participants of sample 1 and the interview questions were raised to the participants of sample 2. After taking the consent to take part in the study, participants were asked to create a code without revealing their identity. Mixed methods were used in the current study to achieve different, multiple perspectives and to confirm the quantitative measures with qualitative data. It is supportive to explain quantitative results.

Sample 1

A self-administrated questionnaire containing the following parts was used to measure different constructs on the current topic was given to sample 1 (students).

\section{Questions on Career exploration}

Two close-ended questions on the awareness of career guidance programmes and the plan of the students were provided. Then, the most preferable career choice of the students was questioned as an open-ended question.

\section{Career choice scale}

A scale developed by the researcher was used to rate how the given factors affect the career choice of students. After analyzing the past literature, the scale included thirteen factors as My talents and skills, Personal interest, the influence of family members, income of the family, knowledge by career guidance program, the impact of a relation or neighbour, school, teachers, and educators, social media, peer group, salary/financial remuneration of the job, professional prestige, Job accessibility/location, Availability/accessibility to the related education in the country (Kim, 2011; Perera, Perera, \& Priyanthika, 2010; Vickneswaran \& Nimalathasan Balasundaran, 2013; Ryan, 2014; Pinto, Galketiya, Jayasingheararchchi, Bandara, \& Wijesinghe, 2016). This is a Likerttype scale that ranges from 1 to $4(1=$ not at all, $2=$ slightly affected, $3=$ much affected, $4=$ very much affected).

\section{Demographic questionnaire}

A demographic questionnaire developed by the researcher, including age, gender, the highest level of education, and District of residence, was included too.

Sample 2

An interview was conducted with Sample 2(teachers). Interview questions were based on a few aspects, including a selfintroduction, questions about career choice, factors affecting the career choice, problems in decision making for a career as well as suggestions to resolve those issues. Items of the scales, interview material, reliability, and validity measures of the constructs used in the study can be found in Appendix A.

Before beginning the survey, all the respondents were informed that participation in this study is not compulsory. The consent was taken from the participants after reading

Table 3: Frequency of students by type of the school

\begin{tabular}{|c|c|c|}
\hline Type of school & Frequency & $\%$ \\
\hline International & 10 & 9.1 \\
\hline National & 10 & 9.1 \\
\hline Private/Semi-government & 30 & 27.3 \\
\hline Provincial & 60 & 54.5 \\
\hline Total & 110 & 100.0 \\
\hline
\end{tabular}

the information sheet and the consent form. Therefore, the right to withdraw when surveying within 14 days of participation was possible. Deletion of data upon withdrawal within 14 days ( 2 weeks) of participation will be done accordingly. In the same way, consent was taken from the participants of the interview, too. But, no requests for withdrawal were made by the participants. Confidentiality of information provided in the questionnaire, as well as the privacy of participants, was cherished. Results were reported in aggregate and unidentified form since a personalized participant code was generated. The applicability and the purpose of the research were explained through the participant information sheet. The stored information will be destroyed within a time frame of five years. A copy of the participant information sheet, debriefing sheet can be found in Appendix

Quantitative data were statistically analyzed by SPSS software, while qualitative data were analyzed by content analysis.

\section{Quantitative data analysis}

Initially, mean scores on the career choice scale were collected. Considering the objectives of the present study, percentage, mean and descriptive statistics were calculated using SPSS software.

The latest version of the International Standard Classification of Occupations (ISCO), ISCO 08, which is a four-level hierarchically structured classification that covers all jobs in the world created by the International Labour Organization, was used to classify the choice of the students. Based on the similarity of the skill levels and skill specialization, the most preferred choice of the students was analyzed. This was apgroups of the jobs are preferred by the students, mostly.

Qualitative data analysis

First, all the data recorded from the interview were transcribed. In the analysis phase following steps were done. Reading the transcripts and making special notes, annotating the transcripts by labeling relevant words, phrases, sentences, or sections with codes, conceptualizing the data by aligning data with critical themes such as factors affecting career choice, problems, and implications. Those data were categorized to conduct a 'content analysis'. Hence, it was easy to tabulate and summarize. In the end, the categories were connected to interpret the results.

\section{RESULTS AND DISCUSSION}

None of the participants were excluded from the analysis since outliers have not been encountered. Quantitative and qualitative data were analyzed separately in order to interpret the results.

\section{Baseline Data}

Quantitative data was taken from the participants in the Kalutara district. $67.3 \%$ of the participants were males, whereas $32.7 \%$ were females. The table 3 illustrate the number of participants according to the school they are studying. plied in the present study to analyze what categories or 
The frequency and percentage of the responses to the question 'Do you think that you have a proper plan about your career path?. Out of all, $92.7 \%$ of the participants reported that they have a proper plan for their career path. However, a career choice was not decided' yet by $7.3 \%$ of students. $59.1 \%$ of the students reported that they were not aware of career guidance programmes in the country. The awareness of career guidance programmes of students who mentioned that they still don't have a career choice was analyzed too. Out of the 19 students who have not yet decided on a career, 10 of them were not aware of career guidance programmes. As a percentage, it is $52.6 \%$.

Awareness of students compared with the type of school was tested using intense analysis and tested by comparing values of the 4 types of schools (subgroups) using SPSS. According to the findings, out of 110 students, $19.09 \%$ of the students from provincial schools, $16.36 \%$ from Private/semigovernment schools, $0.90 \%$ from national schools, and $4.54 \%$ from the international schools are aware of career guidance programmes. It is possible to state that four types of schools are not equal in awareness of career guidance programmes available in the country.

The career choice of students was asked about their most preferable career choice at the moment. Initially, mean values of career choice scales were taken. The responses, their frequencies, and percentages are illustrated in table 4. Career choices of students were categorized based on the ISCO-08 classification as below.
1. Managers
2. Professional
3. Technicians and associate professionals
4. Clerical support workers
5. Service and sales workers
6. Skilled agricultural, forestry, and fishery workers
7. Craft and related trades workers
8. Plant and machine operators, and assemblers
9. Elementary occupations
10. Armed forces occupations

Table 4: Career choice classified according to ISCO-08 classification

\begin{tabular}{|c|c|c|c|}
\hline & & Frequency & Percent \\
\hline \multirow[t]{9}{*}{ Valid } & Not decided & 19 & 17.3 \\
\hline & 1. Managers & 9 & 8.2 \\
\hline & 2. Professionals & 43 & 39.1 \\
\hline & 3. Technicians and associate professionals & 12 & 10.9 \\
\hline & 4. Clerical support workers & 1 & .9 \\
\hline & 5. Service and sales workers & 5 & 4.5 \\
\hline & 7. Craft and related trades workers & 12 & 10.9 \\
\hline & 10. Armed forces occupations & 9 & 8.2 \\
\hline & Total & 110 & 100.0 \\
\hline
\end{tabular}

Only 7 sub-categories of jobs have been preferred by the students. Based on the ISCO-08 classification, the most preferred job sub-category of G.C.E.O/L students is ' 3 '. As a percentage, it is $39.1 \%$. Included jobs in this category which are preferred by the students are lecturer, lawyer, medical-related jobs (doctor, nurse, psychiatrist, eye surgeon, dental Surgeon), engineering fields (civil/mechanic engineer, aeronautical engineer, Sound controlling Engineer) nurse, lawyer, teacher, magistrate coroner, Information Technology field (IT-related jobs, Software Developer, software/computer engineer), Mathematics stream, surveyor, artist, journalist, and announcer. Category no.6, 8, 9 were not preferred by the students. These include skilled agricultural, forestry, and fishery workers, plant and machine operators, and assemblers, and elementary occupations.
Factors affecting career choice of students was tested using descriptive statistics in SPSS software. The results confirmed that talents and skills, personal interest, the influence of family members, income of the family, knowledge by career guidance program, the impact of a relation or neighbor, school, teachers and Educators, sibling/relation's impact, social media, peer group, salary or financial remuneration of the job, professional prestige, job accessibility/location, social media, availability/accessibility to the related education in the country play a role as the determinants of career choice of G.C.E. O/L students. Out of them, the most influential determinant was personal interest. Mean ratings of the factors are illustrated in table 5.

\section{Table 5. Overall mean ratings of the factors that affect career choice}



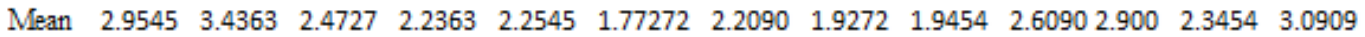




\section{Qualitative Data}

According to the content analysis of the qualitative data, themes or thematic areas were divided.

\section{Career exploration}

One of the elaborative answers includes that it is a turning point only for the students who are not qualified for O/Ls and those who cannot follow other courses because of financial issues. Some other responses include "Yes if the students get through the $\mathrm{O} / \mathrm{L}$ exam they will be able to lay the foundation for their career after doing the $A / L$ exam." and "Yes, because the subjects that students chose for A/Ls depend on the results of the $\mathrm{O} / \mathrm{L}$ exam. The career path also depends on that." specifically.

proper understanding of students on their career path: While most of the interviewees answered "no" to the question of whether $\mathrm{O} / \mathrm{L}$ students have a proper understanding or plan on their career path, two responses mentioned that only a few have a proper understanding. One elaborative response includes, "I think some of them are aware. But, it's good to do different tests to choose a career. Then, the students can go in the career even though they couldn't get through O/L exam."

Factors that determine the career choice of Sri Lankan students after their G.C.E.

Ordinary Level Exam: Apart from the factors that determine the career choice of Sri Lankan students after their G.C.E. Ordinary Level Exam, which was analyzed by the quantitative data, following is the data of factors collected by qualitative data. Family background, the economic stability of the family, passion, salary, gender, role models, friends, environment, demands/ trend in the job market Forces of job market, Financial status, opportunities to migrate to another country, Self-awareness, Social development, Exam results, influence of the parents, ideas of peers/friends, impact of the teachers, economical definitions given by the internet and media, skills of the students, self -awareness, attitudes and the intelligence of the parents, family background, educational level, leadership skills, talents in sports, family background, Pressure from the family, prestige, job market, salary of the job, recognition of the job, talents, and skills of the students, passing Maths in O/L, willingness to work in the field, interest and parental influence

Problems faced when deciding the career: In this study, the significant problems for the students when deciding on a career were also assessed by interviews conducted with sample 2 (well-experienced school staff/teachers), According to the findings, it has been established that the following are the significant problems faced by the students.

1. Lack of understanding and awareness on career choice and fields of jobs

2. Not having interest or the willingness in the field they study

3. Lack of self-awareness on their talents

4. lack of motivation

5. Financial or economic background

6. the social condition of their lives

7. cultural background,

8. lack of information in marketing decisions

9. not identifying differences in nature of different careers

10. parental influence or the pressure

11. inability to get the correct advice and seek support on career choice
12. non-availability of the subjects that students are interested in pursuing a career

13. educational barriers such as lack of teachers to follow the preferable subjects of the students

14. Pressure from the educators, teachers, or the society

15. Personality issues

16. not having proper goals or hopes.

17. English knowledge

18. peer's influence

19. Availability of the opportunities in the country

20. Not possessing qualifications required for the jobs Impacts of career choice: The above-mentioned issues would cause students to decide on a wrong career path or a career that they are not fit in. The issues in career choice often lead to high levels of psychological problems. These include low self-esteem and low self-efficacy, as well as low cognitive abilities. Similarly, those who have made a career decision were less prone to be depressed than students who have not decided on a career. It has been found that career decisiveness is positively related to high levels of self-efficacy, optimism, self-esteem, low levels of pessimism, and a low tendency to perceive external barriers. In the same way, those who seek help for their career choice problems were found with higher levels of psychological problems and less effective coping strategies (Kunnen, 2014). In a study, the editors of Career hunters found that 9 out of 10 people aged between 21 and 65 years regret rushing their career choice. When students have to pick a university course at random, they were pushed to decide as they are 'running out of time'. Work-related stress and depression rate were high, with a prevalence rate of 1,500 for every 100,000 workers because of a wrong career (Hunter, 2017). Therefore, career decisions affect the psychological well-being of a person. There is a tendency that it also increases the suicidal rates of people. $2.5 \%$ of all suicides in India are due to unemployment according to the National Crime Records Bureau (SureJob, n.d.).One of the most severe impacts of wrong career choice is unemployment or joblessness as well as working on unsatisfied salaries. For instance, In India, only seven percent of MBAs are employable due to lack of skills and over 200,000 doctors are unemployed (SureJob, n.d.). The pressure of parents on the students to follow a certain profession leads to different issues. They ignore the inborn skills of their student and force them into professions for which they lack interest and skills (SureJob, n.d.). Using over half of the 3,000 students GTI Media survey conducted a study and explored $69 \%$ of the participants were influenced or forced by their parents in their choice of university. Similarly, $20 \%$ of students currently enrolled at university stated that they would have picked a different course if given the chance. Overall, $18 \%$ of them regret their choice of degree. $18 \%$ of the 1,805 participants mentioned that the major cause of their disappointment was the lack of initial research (Hunter, 2017). When considering the economic impacts of career choice, changing careers is a significant aspect. If someone changes their career or field of study, it would cost more. These include the cost of living and a salary which would give up to gain some relevant working experience. Productivity of work is also reduced by working in a job that doesn't make a person satisfied. Then this leads to financial losses of the companies too (Hunter, 2017). Financial crisis due to the wrong career is also another economic impact. Inability to repay educational loans and default leads to severe financial crises (SureJob, n.d.). 
Improving awareness of different career choices: Different suggestions to improve awareness on different career paths or choices of students were obtained by the qualitative data as follows.

Encourage self-awareness through printed, electronic and social media, guide students to search online courses, organize awareness programmes such as seminars, workshops, camping, and leadership training

Providing a better childhood for students, programmes for both parents and students to develop attitudes

Organizing career guidance programmes for students, parents, and teachers, organizing practical and field training for technical /technological subjects

Understanding the value of learning the subject while guiding them to use books and do self-studies on the subjectrelated matters they like to study. Encouraging students to enhance creative skills rather than focusing on exams. Another important thing is that education should not be mental stress or a burden on the students. I think all the teachers should be aware of educational psychology.

giving the opportunity and guidance to choose a subject they like from grade 9 onwards, conducting career assessment tests such as 'career key' to decide the subjects to do for the $A / L$ exam, educating the teacher in career guidance and counselling, conducting career guidance day or exhibitions

Providing career guidance and goals to have a proper career plan. And also giving opportunities to identify their skills and talents.

More opportunities should be provided for the students. And also it's important to provide them with career guidance programmes.

It is important to let the students identify their facilities and provide adequate facilities. And also a variety of different paths or choices should be there,

Giving career guidance as well as making them aware of the opportunities.

Organizing career guidance programmes, improving the financial status of the country or providing facilities such as loans or aids

Four types of schools were not equal in awareness of career guidance programmes available in the country. It is possible to state that 'personal interest' is found to be the most influential determinant of career choice. Out of 110 participants, $59.1 \%$ of the students were not aware of career guidance programs available in the country $.7 .3 \%$ of the students have not yet decided on a career choice. Overall mean ratings of the determinants of career choice reported that the participants choose a career based on personal interest, mostly. The most preferred job sub-category of G.C.E. O/L students is ' 3 ' based on the ISCO-08 classification. As a percentage, it is $39.1 \%$. Twenty issues related to career choice, their impacts, and solutions including organizing career guidance programmes, conducting career choice tests, and providing facilities for education were identified.

Initially, the first objective of the study, which was discovering different career choices of $\mathrm{O} / \mathrm{L}$ students, was done by the quantitative data of the research questionnaire. The second objective, which is the comparison of the determinants that affect career choice between the graduates/undergraduate and school students, was done by the literature review as well as through both quantitative and qualitative data collected by the questionnaire and interview. The other objectives which are identifying the awareness of students on available career paths and career guidance programmes, identifying the different factors determining the career choice of students, identifying the problems that O/L students in Sri Lanka was successfully done by the current mixed-method study. The problems that O/L students in Sri Lanka face when deciding their career choice, psychological and social impacts of choosing a career, and understanding the implications to improve awareness on career paths or choices for students in Sri Lankan context were done by qualitative data.

The present study mostly focused on the factors which affect the career choice of students. Personal factors or social factors have not been tested in-depth. Lack of prior research studies taken from school students on the topic was displayed when comparing the current findings with the prior studies. But, the factors related to career choice were tested among graduates and undergraduates. Therefore, the results of the current study were evaluated by comparing the studies done with graduates and undergraduates. One of the findings also ties with previous studies by Perera \& Priyanthika in minor methods. The factors that affect choosing a job include the salary of the job, other benefits, opportunity to develop skills and competencies, freedom of decision making, working condition, social image, and respectability to both categories of job seekers and job offers. The factors that are not significant in choosing a job were also discovered. These include challenges, promotion, personal welfare facilities (Perera, Perera, \& Priyanthika, 2010).

Similar findings to a study done by Vickneswaran \& Nimalathasan Balasundaran were established. Factors influencing career choice among the second-year undergraduate students of Faculty of Management Studies and Commerce, University of Jaffna, Sri Lanka have been examined previously such as personal or self, family and relations, current job market, geographical area, occupational, and some others It has been identified that student face difficulties when they have to select their specialization field since this selection is very crucial everyone to recognize them in the world (Vickneswaran \& Nimalathasan Balasundaran, 2013). But in the current study, the above factors were considered as minor determinants.

Another study by Beggs, Bantham, \& Taylor suggests that the salary and benefits of the job are not significant factors that determine the career path (Beggs, Bantham, \& Taylor, 2008). This is grounded by the current study, too. The mean rating for the 'Salary/Financial Remuneration of the job' is low in the current study.

Some other significant factors of graduates to select a job include relaxation, wage/salary, benefits convenience, management practices, culture, status, social acceptance, job satisfaction, security, freedom, career development, branches of the organization, and flexibility (Kumara, 2005). Many learners are unsuccessful in finding occupational pathways due to a lack of career guidance at schools. (Education for All, UNESCO, 2010)

As revealed via a survey by Mindler, online career guidance, and counseling organization, it was found that over $93 \%$ of Indian students aged between 17 and 21 years are aware of only seven career options in India out of around 250 career options. Using 10,000 youth respondents, it has been established that $23.52 \%$ of the participants consider engineering while $11.81 \%$ accounting and finance. And also $9.56 \%$ would prefer computer applications, $8.08 \%$ medicine, $6.71 \%$ management, $6.06 \%$ designing, and $4.38 \%$ for the law (SureJob, n.d.). Similar findings were reported by the current study 
when analysing the frequencies of jobs preferred by students. Under the above finding, the current study found that students preferred the subcategory of professionals, mostly. Other than that, only a few responses were found to be in the other 7 groups. Three categories were ignored by the students, such as the categories of skilled agricultural, forestry, and fishery workers, plant and machine operators, and assemblers and elementary occupations.

The findings are not limited to organizational or individual purposes. But, they could be used from a societal perspective, influencing the economic and social conditions of the country. For example, getting profit through marketing practice can lead to a better economic condition of the country. The requirement of the policy framework with the essential need of career study programmes and career guidance for general education was emphasized in the current study. The development of career guidance and counseling services has been a key policy objective since the mid-1990s and highlighted in major reports and policy documents such as Education Sector Evaluation (2007), National Policy Framework on Higher Education and Technical and Vocational Education (2009), National Policy on Career Guidance in Schools (2010). Circular 2001/16 was proposed by The Parliamentary Advisory Committee of 2010 to activate career guidance and counselling at schools and to avoid shortcomings associated with implementing guidance and counselling at schools. Other related services, including information on vocational training, entrepreneurship development, and trends of the labour market, were emphasized too. According to National Policy Framework on General Education (2003), a very low priority in the general education system for career guidance programmes had been received during the last four decades. Therefore, it is recommended to plan a policy for career guidance education, to establish a Career Guidance Unit under a senior officer at the Ministry of Education to guide overall implementation of career guidance/career education, to properly train teachers in career guidance, and career guidance coordination school wise. Apart from these, organizational arrangements at the school level need to be structured with the identification of the role and responsibilities of Principal, Career Guidance Teacher, and Other Teachers in career guidance. Parents are not a significant target group, according to the findings of the study. However, parents play a major role in guiding children in Asian countries and hence significant effort must be made to reach this target group with relevant career guidance information. This could be done at the school level as well as by public mass media(National Education Commission, 2016).

Important implications for the educational sector and professionals in career counselling and guidance were determined by the results of the current study. Career choice counseling is recommended as a standard component of a general prevention program from the psychological effects of career choice (Kunnen, 2014). The findings could be applied by career guidance counselors to encourage students to have a vision and focus on a job from the period of G.C.E. $\mathrm{O} / \mathrm{L}$. In the current study, it was also found that students prefer jobs of particular subcategories over others. Hence, students can be encouraged to prefer other matching and demanding subcategories which are often not preferred by the students.

To prevent the psychological and social impacts of not selecting the right fit or the right job, it is highly recommended by the teachers to organize career guidance programmes in the school according to the current findings. Findings of a study by Pinto, Galketiya, Jayasingheararchchi, Bandara, \& Wijesinghe also supported that career choice were positively related to the period of exposure to clinical specialties during the undergraduate curriculum education about the career choice and its availability influences this decision. It has been found that at least a few hours of career guidance would improve their higher education choice of medical graduates (Pinto, Galketiya, Jayasingheararchchi, Bandara, \& Wijesinghe, 2016). This finding can be applied to schools as well.

Significant influences of the environment, as well as explanatory factors such as status, outcome expectations, and job stability on career plans, were found by Carrico, Holly M. Matusovich, \& Paretti. The patterns that emerged related to contextual factors and career choice emphasized the importance of culture and context when investigating how students decide on career choice. Moreover, the patterns offer insights career coaches, counselors, and educators can use in supporting students' post-high school career planning (Carrico, Holly M. Matusovich, \& Paretti, 2017).

Most educational institutes ignore career guidance and underestimate the values of career counselors (SureJob, n.d.). But, the value of career guidance programmes was highlighted in the interviews.

In the current study, only one participant mentioned in the interview that career assessment tests are important to solve issues in choosing a career. This is supported by editors of Career Hunter too. According to them, a career test in the early stages of life will help to avoid confusion and bad career choice. This would cause the self-satisfaction and happiness of an individual. These are now widely used online. Online career testing platform supports finding career matching skills and interests of the users without wasting a ridiculous amount of money and time on something that people don't care about (Hunter, 2017).

Apart from that, providing financial facilities, adequate opportunities to study in the preferred field, as well as increasing availability of careers, were suggestions by the interview. The sample size of the current study was small to generalize the study results to the entire population since only 110 students and 10 teachers were taken. The study could have been done according to the different streams to obtain better results. The reasons and factors for not selecting some categories of jobs were not tested in the current study. It is better to understand what makes people prefer some jobs over others.

The sample of the present study is limited only to the geographical area of the Kalutara district(Western Province). With time constraints and financial factors, the research was limited to selected types of schools in Kalutara district. It is recommended that this research be carried out island-wide across all provinces. If both questionnaire and interview will be conducted in all the provinces, it will give a more comprehensive picture. Therefore, generalizing the overall results to the whole Sri Lankan population should be done with caution. More qualitative researches are required to investigate the basis of the results too.

\section{CONCLUSION}

It is important to have a career plan as the G.C.E. O/L exam is crucial in deciding the future of Sri Lankan students. Specially, those who are not qualified for G.C.E. O/Ls are required to choose options for their career. Choosing the wrong career or a path that an individual is not fit for could lead to adverse psychological, economic, and social effects. 
It is also important to be updated with the trending and emerging careers that are demanded by the job market. Otherwise, the qualifications or the skills that a person possesses will be in vain. The need for proper knowledge, awareness, and understanding of careers, the job market, and the nature of jobs play a key role in that sense. That is why programmes for career guidance, career counseling, career assessment tests, and awareness camps in schools are found to be essential. To sum up, the requirement of the policy framework with the essential need for career study programmes and career guidance for general education is an important aspect.

\section{ACKNOWLEDGMENTS}

The author would like to acknowledge the Postgraduate Institute of Humanities and Social Sciences (PGIHS) at the University of Peradeniya, Sri Lanka.

\section{REFERENCES}

Beggs, J., Bantham, J., \& Taylor, S. (2008). Distinguishing the Factors Influencing College Students' Choice of Major. College Student Journal, 42(2), 381-394.

Bradbery, J. (2011). Oxford American Dictionary for learners of English. Oxford: Oxford University Press.

Carrico, C., Holly M. Matusovich, \& Paretti, M. (2017). A Qualitative Analysis of Career Choice Pathways of College-Oriented Rural Central Appalachian High School Students. Journal of Career Development, 46(2), 94-111.

Cenkseven-Önder, F. (2017). High school students' career decisionmaking pattern across parenting styles and parental attachment levels. Electronic Journal of Research in Education Psychology, 8(10). PP.

Creswell, J. W. (2009). RESEARCH DESIGN Qualitative, Quantitative, and Mixed Methods Approach (3rd ed.). SAGE Publications. In

Department of Examinations, S. L. (2019). Performance of candidates, G.C.E.(O/L)Examination - 2019.

Hughes, R., \& Balasuriya, L. (2003). Education and Employment: Sri Lanka at crossroads. 9th International conference on Sri Lanka Studies, Sri Lanka.

Hunter, C. (2017, February). The Shocking Cost of Making a Wrong Career Choice. Retrieved 09 10, 2020, from Prnewswire.com: Prnewswire.com

Kim, M. (2011). The Relationship Between Thinking Style Differences and Career Choices for High-Achieving Students. Roeper Review, 4(33), 252-262.

Kim, M. (2011). The Relationship Between Thinking Style Differences and Career Choices for High-Achieving Students. Roeper Review, 33(4), 252-262.

Kumara, K. (2005). State as the employment of last resort: a critical review of key determinants on job selection of undergraduates and graduates in the private and public sector organizations. Contemporary public policy issues in Sri Lanka, Department of Public Administration (pp. 86-110). Faculty of Management Studies and Commerce, University of Sri Jayewardenepura,

Kunnen, E. (2014). The effect of a career choice guidance on selfreported psychological problems. Frontiers in Psychology, 5.

The Ministry of Education. (2020). Annual School Census of Sri Lanka Final Report 2020.

National Education Commisison. (2016). Study On Career Guidance In General Education In Sri Lanka. National Education Commisison.

Perera, G., Perera, J., \& Priyanthika, H. (2010). Job Preferences of Management Undergraduates: Special Reference of Management Undergraduates from the University of Sri Jayewardenepura. Human Resource Management Journal, 1(1).

Pinto, V., Galketiya, K., Jayasingheararchchi, D., Bandara, S., \& Wijesinghe, D. (2016). Career preferences of medical undergraduates of Sri Lanka; the influence of exposure to specialties on career choice. South-East Asian Journal of Medical Education, 10(2), 55.

Ryan, C. (2014). Factors Influencing Adolescent Career Choice with Particular Emphasis on the Role of Personality.
SureJob. (n.d.). Shocking Reasons \& Effects of Making a Wrong Career Choices. Retrieved from Sure Job: https://surejob.in/wrong-careerchoices.html

Vickneswaran, A., \& Nimalathasan Balasundaran. (2013). Factors Influencing In Career Choice Of Second Year Undergraduate Students: A Case Study Of Faculty of Management Studies \& Commerce, University Of Jaffna, Sri Lanka. International Journal of Social Science \& Interdisciplinary Research, 2(11). PP.

Wickramaratne, W. (2018). Role of Career Preference Factors in Predicting Graduates' Employability. International Journal of Business and Social Science, 9(11). pp 
